Original Research

\title{
Possibilities for Reducing Combustion Engine Fuel Consumption and Gas Emissions
}

\author{
Michal Puškár ${ }^{1 *}$, Melichar Kopas , Jaroslava Kádárová2 ${ }^{1}$ Štefan Kender³, \\ Dušan Sabadka ${ }^{3}$, Dušan Puškár ${ }^{1}$, Ján Lumnitzer ${ }^{1}$ \\ ${ }^{1}$ Faculty of Mechanical Engineering, TU Košice, Department of Engineering for Machine Design, \\ Automotive and Transport, Letná 9, 04001 Košice, Slovak Republic \\ ${ }^{2}$ Faculty of Mechanical Engineering, TU Košice, Department of Industrial Engineering and Management, \\ Letná 9, 04001 Košice, Slovak Republic \\ ${ }^{3}$ Faculty of Mechanical Engineering, TU Košice, Department of Automotive Production, \\ Mäsiarska 74, 04001 Košice, Slovak Republic
}

Received: 29 April 2017

Accepted: 11 July 2017

\begin{abstract}
Problems concerning fuel consumption and emissions of piston combustion engines are always very topical. Therefore, questions regarding combustion engine emissions should be analysed and solved continually in order to reduce the negative impacts caused by using these engines. This article is focused on engine fuel systems and pre-ignition maps that significantly influence emissions production related to motorcar engines. Our research-development team performed a global investigation work, which includes experimental measurements using a small-volume single-cylinder piston combustion engine. This kind of engine is also applied in small ships, and in our case it is installed in a special experimental vehicle designed for a well-known international competition: the Shell Eco-Marathon. The main task of the abovementioned research activities was to minimize engine fuel consumption and reduce the nitrogen oxides in the exhaust gases. The whole combustion process inside the given engine was considerably improved and in this way fuel utilization efficiency was positively influenced.
\end{abstract}

Keywords: combustion engine, fuel consumption, gas emissions, pre-ignition map, fuel map

\section{Introduction}

It is a well-known fact that reducing fossil fuel resources, together with the necessity of making piston combustion engine operation more ecological, is a very serious worldwide problem. Despite the fact that new, alternative solutions for driving systems have been introduced, the standard piston combustion engine

*e-mail: michal.puskar@tuke.sk remains the most often used type of driving unit, which has been determined for road transport applications and for a large category of ships, too.

Improving piston combustion engine efficiency and eliminating the ecological disadvantages is possible by means of a specific motor-management system using the data field changes implemented within the engine control unit. Modifying the engine control system is possible after editing the individual data field sections in order to achieve partial changes in the individual engine speed spectra. The control system of the driving unit consists 
of algorithms operating with specific and complex data interrelationships, whereas the control unit software is based on numerical combinations.

\section{Material and Methods}

\section{Control System of Driving Unit}

The correct operation of the combustion engine control unit requires a continuous flow of the input signals. Today there are applied control units functioning according to complicated control algorithms. The more complex these algorithms, the larger the amount of actual parameters that must be distributed. The input values are measured by means of the sensors placed directly on the combustion engine, and consequently these values are processed and evaluated by the control unit.

Taking into consideration a principle of functionality, the control unit can be characterised and described as a multifunctional control microcomputer, whereas the main task of it is receiving the input data and following their processing. The control unit performs a correction of the volume and length of the injected fuel charge in order to optimise the engine power output parameters as well as to reach favourable fuel consumption and lowlevel emission values [1-2].

Optimizing the fuel-air mixture ignition in the combustion engine is another important activity of the control unit. It is necessary to pay attention to the ignition system while solving the whole motor-management system. High-speed spark ignition engines are especially sensitive to the exact moment of fuel mixture ignition [34].

The moment of ignition in the case of the standard spark ignition engines is determined with regard to optimal fuel consumption and emissions reduction. On the other hand, the situation in the case of racing car engines is different, because such kinds of engines are oriented toward maximum engine operational efficiency. The most important factors influencing correctness of the ignition process are: engine temperature, temperature and composition of the exhaust gases, suction air temperature, etc. These factors must be taken into consideration while forming the data fields specified for the control unit. The optimal ignition maps are created using a mathematical simulation of pre-ignition, as well [5].

\section{Experimental Model and Measuring Equipment}

Modification of the data fields was performed by means of specific software [6]. Proposal of the data fields was realised on the real driving unit installed in the experimental vehicle, which is especially designed for the international Shell Eco-Marathon competition. Namely, it is a HONDA four-stroke piston combustion engine of type GX25 with the engine performance characteristics presented in Fig. 1.

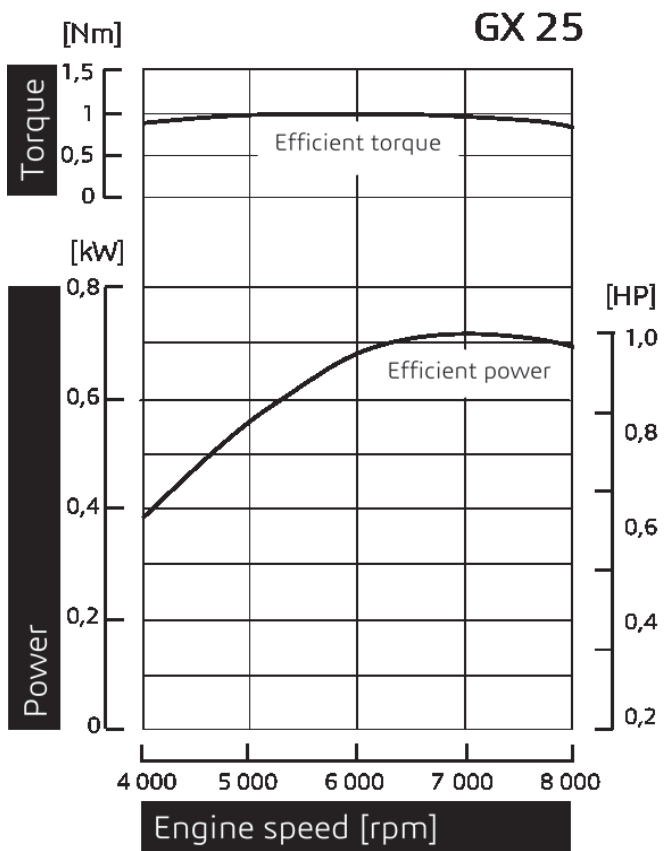

Fig. 1. Performance characteristics of the experimental engine.

The transistor coil ignition (TCI) system originally installed in the experimental engine was replaced by a complex electronic fuel injection (EFI) system from the Ecotrons company (Fig. 2). This new system is applied as a complex set intended for small-volume engines. The system control module enables managing the ignition and injection system, together with recording engine operational data.

The sensors installed in the injection module are sensing data necessary for correct operation of the control

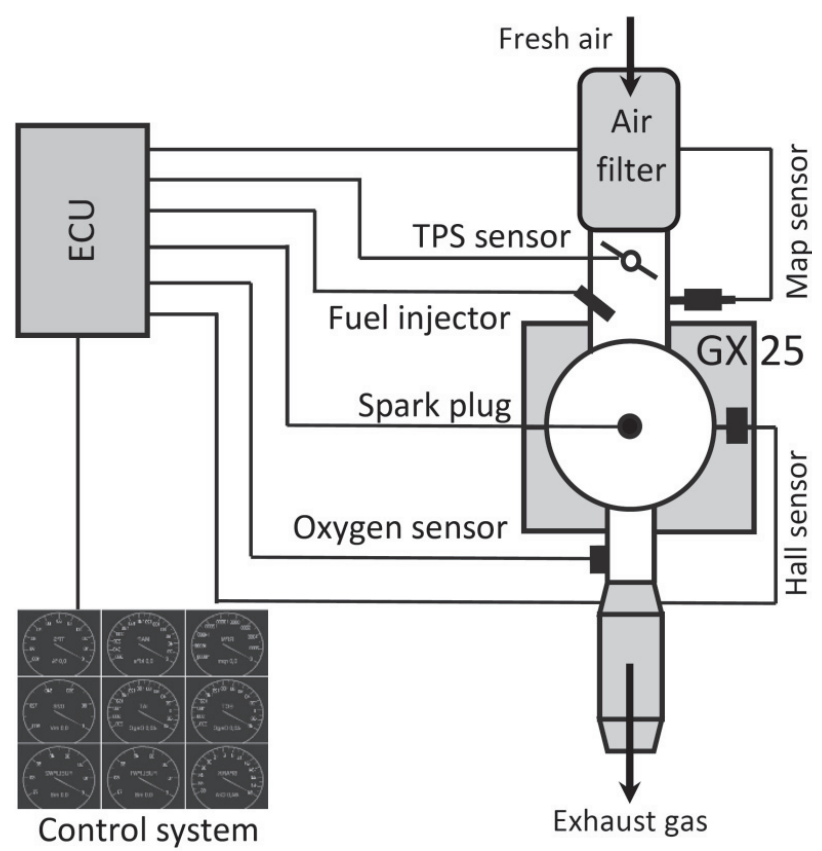

Fig. 2. Applying the EFI system for the experimental engine. 
unit [6]. Thanks to the data obtained from the measuring process, it is possible to operate with real values in order to modify the control unit data fields. The $\lambda$-values measured by the exhaust gas oxygen sensor (lambda sensor) were obtained using INOVATE MOTOSPORTS 3837 LM-4 measuring equipment.

\section{Creating the Individual Data Maps}

The individual data maps were created by means of the software product ProCal, which is an integrated part of the installed EFI system. This software enables online monitoring of the engine operational parameters, e.g., engine speed (rpm), suction pipe pressure $(\mathrm{kPa})$, throttle position ( $\%)$, and $\lambda$-values. These input data are important for creating the fuel maps and pre-ignition maps in order to reach the best possible final effect.

After interconnecting the EFI control unit with the modification component (PC) by means of the KDS interface, the ProCal software displays such settings of the fuel maps and pre-ignition maps, which are typically used according to the recommendation from the producer Ecotrons with regard to the given engine [6]. Research and development of the new data maps are based on the above-mentioned standard settings (Table 1, Fig. 3, Table 3, and Fig. 4) that were optimised consequently.

\section{Innovation of the Fuel Map for the Experimental Engine}

Proposal of the fuel maps is based on the concrete design solution of the given driving unit. It is necessary to keep the suitable fuel-air mixture composition on various operational conditions during the whole optimisation process [7-8].

Each of the motor-management software products describes the engine-loading status using information about a throttle position. This position is sensed by the throttle position sensor (TPS), namely in the range $0-100 \%$. Range of engine loading can also be described by the value of suction pressure, which is generated in the suction pipe, whereas the manifold absolute pressure (MAP) sensor is reading the under-pressure value.

However, ProCal, which was applied for creating the driving unit fuel maps, is utilizing another, non-standard principle. Unlike the standard motor-management software products, ProCal does not describe the actual loading of the driving unit by throttle position and engine speed. The fuel map in this case is not created according to the above-mentioned two variables and length of the injector impulse, because creation of the fuel maps is influenced by the various factors, for example by altitude above sea level, air temperature, vehicle speed, etc. Therefore, ProCal automatically recalculates the variable value "LOAD" according to the ratio TPS/rpm such that the value "LOAD" is a ratio between the real amount of suction air and the theoretical amount, whereas it is given as a percentage. Volume of the injected fuel is also given as a percentage; it is a ratio between volumetric efficiency and flow passing through the injection nozzle.

It is necessary to know engine volumetric efficiency in order to create the fuel map correctly, with regard to the fact that volumetric efficiency is a decisive factor for determining the fuel injection time interval. The highest volumetric efficiency of the given experimental engine is reached within the engine speed range from 6,500 to $7,500 \mathrm{rpm}$. The injection system contains a type EFIJ solenoid injector. The proposed fuel map requires information about the value of the fuel volume flowing through the injector nozzle and about the fuel system pressure. In our case the flow volume of the applied injector was 80 g.min ${ }^{-1}$ and the fuel system pressure was $294 \mathrm{kPa}$.

The fuel map was developed on the assumption that it is necessary to reach a lean fuel-air mixture, namely with $\lambda$-values of 1.07-1.20. The original fuel map was applied as an initial base and the following procedure of data transcription was performed using the data table obtained from ProCal, taking into consideration the final efficiency of the combustion process (Table 1 and Fig. 3).

The $\lambda$-values were measured and recorded in the intervals of every $500 \mathrm{rpm}$ within the whole engine speed

Table 1. Standard and modified fuel maps.

\begin{tabular}{|c|c|c|c|c|c|c|c|c|c|}
\hline \multicolumn{10}{|c|}{ Standard fuel map } \\
\hline TPS position $(\%)$ & 0,000 & 6,000 & 12,000 & 18,000 & 24,000 & 30,000 & 36,000 & 42,000 & 48,000 \\
\hline Amount of injected fuel (\%) & 0,000 & 1,500 & 4,688 & 12,000 & 41,063 & 65,063 & 90,000 & 117,000 & 150,000 \\
\hline TPS position $(\%)$ & 54,000 & 60,000 & 66,000 & 72,000 & 78,000 & 84,000 & 90,000 & 96,000 & 102,000 \\
\hline Amount of injected fuel (\%) & 171,000 & 189,938 & 207,000 & 222,938 & 231,938 & 245,063 & 257,063 & 261,938 & 266,063 \\
\hline \multicolumn{10}{|c|}{ Modified fuel map } \\
\hline TPS position (\%) & 0,000 & 6,000 & 12,000 & 18,000 & 55,008 & 57,000 & 63,000 & 67,992 & 72,000 \\
\hline Amount of injected fuel (\%) & 0,000 & 1,500 & 4,688 & 12,000 & 41,063 & 65,063 & 90,000 & 125,063 & 135,000 \\
\hline TPS position $(\%)$ & 75,000 & 78,000 & 79,008 & 82,008 & 84,000 & 85,008 & 87,000 & 88,008 & 91,008 \\
\hline Amount of injected fuel (\%) & 138,000 & 140,063 & 143,063 & 144,000 & 146,063 & 146,063 & 147,000 & 147,938 & 149,063 \\
\hline
\end{tabular}



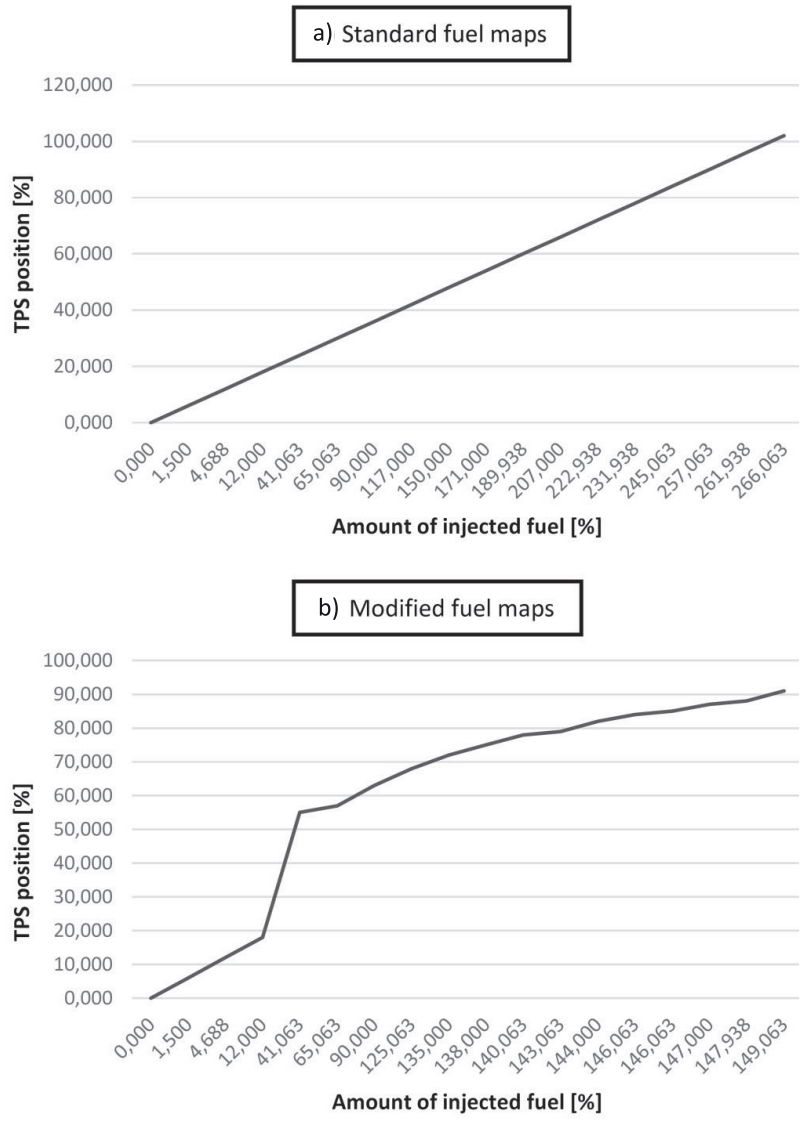

Fig. 3. Presentation of the standard and modified fuel maps.

spectrum after modifying the fuel map as well as after pre-programming this fuel map into the control system (Table 2). Consequently, we performed the required corrections, namely of reducing the fuel injection value in the rich mixture areas by a correction made in the concrete data field part.

\section{Innovating the Pre-Ignition map for the Experimental Engine}

ProCal enables not only editing of the fuel map, but also data changing in the pre-ignition map. Optimizing the pre-ignition map is based on the engine design solution, because the real engine construction influences the process of the fuel mixture combustion in the engine combustion area. The combustion process of the fuel mixture runs very fast in the case of small-volume engines. Therefore it is necessary to dispose of a possibility to change the value of advanced ignition. The compression ratio of the tested driving unit is $8: 1$. This fact causes a
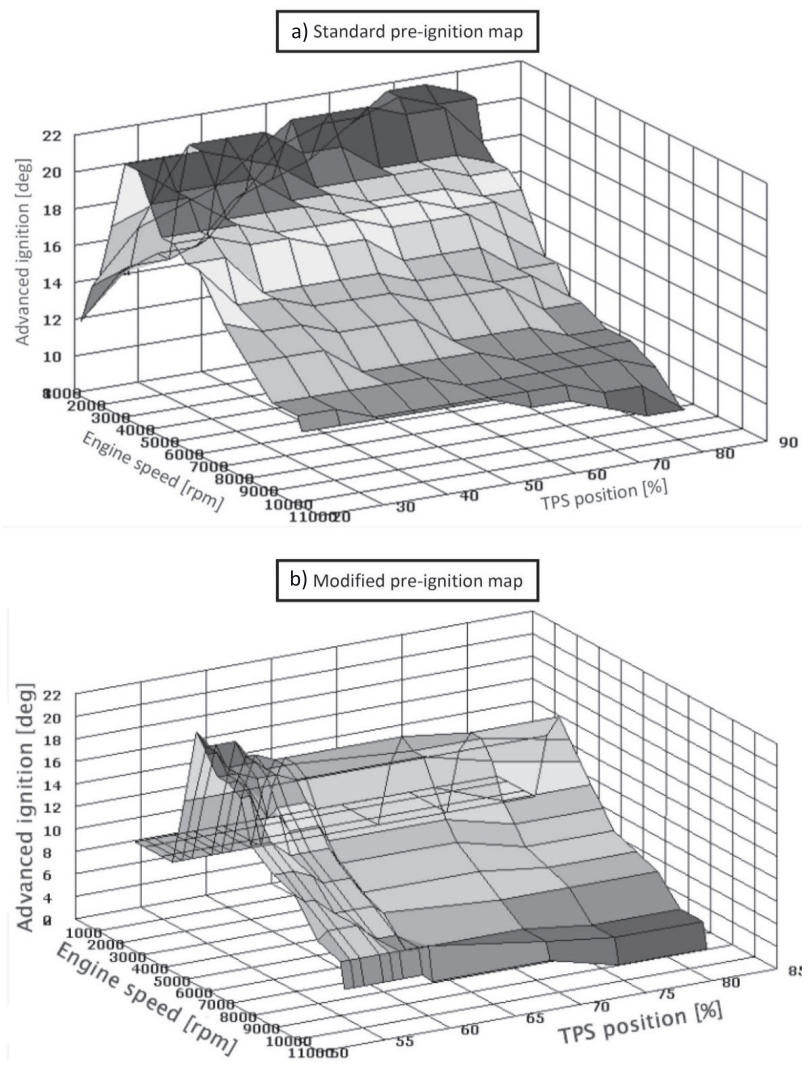

Fig. 4 3D presentation of the standard and modified pre-ignition maps using the software ProCal.

fast running of the mixture combustion process, whereas the pre-ignition value is from $4^{\circ}$ to $20^{\circ}$ before the top dead centre. Another relevant factor that influences behaviour of the mixture combustion is the fuel octane number. It is a well-known fact that the higher value of the octane number also means better fuel resistance to the detonation combustion [9].

ProCal utilizes the next variable values: throttle position, engine speed, and ignition advance angle. Insomuch that the detonation combustion sensor is not a part of the injection module, it is necessary to find the optimal ignition advance value.

Optimizing the pre-ignition map using ProCal can be realised either by modifying data in Table 3 or by the changes made in the 2D or 3D coordinate system (Fig. 4).

The pre-ignition map was edited by changing data in the data table (Table 4). The individual values can be changed from the plus values to the minus values.

The important part of the pre-ignition map is the engine speed area with the highest power output of the

Table $2 . \boldsymbol{\lambda}$-values after modifying the data fields.

\begin{tabular}{|c|c|c|c|c|c|c|c|c|c|c|}
\hline Engine speed $(\mathrm{rpm})$ & 4,000 & $\mathbf{4 , 5 0 0}$ & $\mathbf{5 , 0 0 0}$ & $\mathbf{5 , 5 0 0}$ & $\mathbf{6 , 0 0 0}$ & $\mathbf{6 , 5 0 0}$ & $\mathbf{7 , 0 0 0}$ & $\mathbf{7 , 5 0 0}$ & $\mathbf{8 , 0 0 0}$ & $\mathbf{8 , 5 0 0}$ \\
\hline $\mathbf{1}^{\text {st }}$ measuring $(\boldsymbol{\lambda})$ & 0.99 & 0.98 & 1 & 1.07 & 1.15 & 1 & 0.99 & 1.06 & 1.1 & 1.11 \\
\hline Final measuring $(\boldsymbol{\lambda})$ & 1.07 & 1.09 & 1.09 & 1.1 & 1.14 & 1.16 & 1.14 & 1.14 & 1.12 & 1.13 \\
\hline
\end{tabular}


Table 3. Standard pre-ignition map.

\begin{tabular}{|c|c|c|c|c|c|c|c|}
\hline \multicolumn{8}{|c|}{ Standard ignition map } \\
\hline & & \multicolumn{6}{|c|}{ TPS position (\%) } \\
\hline & & 20,250 & 26,250 & 32,250 & 38,250 & 44,250 & 50,250 \\
\hline \multirow{16}{*}{$\begin{array}{l}\text { Engine speed } \\
\text { (rpm) }\end{array}$} & $1,200,000$ & 12,000 & 14,250 & 15,000 & 15,000 & 17,250 & 18,000 \\
\hline & $1,680,000$ & 14,250 & 15,000 & 15,000 & 15,750 & 18,000 & 20,250 \\
\hline & $1,980,000$ & 15,000 & 17,250 & 18,000 & 18,750 & 20,250 & 21,750 \\
\hline & $2,460,000$ & 18,000 & 18,750 & 21,750 & 21,750 & 21,750 & 20,250 \\
\hline & $3,000,000$ & 21,750 & 21,750 & 21,750 & 21,000 & 20,250 & 18,750 \\
\hline & $3,540,000$ & 21,750 & 20,250 & 20,250 & 20,250 & 18,750 & 18,750 \\
\hline & $4,020,000$ & 20,250 & 20,250 & 18,750 & 18,750 & 18,750 & 18,000 \\
\hline & $4,500,000$ & 18,750 & 18,750 & 18,750 & 18,000 & 18,000 & 18,000 \\
\hline & $4,980,000$ & 18,750 & 18,750 & 18,000 & 18,000 & 17,250 & 17,250 \\
\hline & $5,520,000$ & 18,000 & 18,000 & 15,750 & 15,750 & 15,750 & 15,750 \\
\hline & $6,000,000$ & 18,000 & 15,750 & 15,750 & 15,000 & 15,000 & 15,000 \\
\hline & $7,020,000$ & 15,750 & 15,000 & 15,000 & 14,250 & 14,250 & 14,250 \\
\hline & $7,980,000$ & 14,250 & 14,250 & 14,250 & 12,750 & 12,750 & 12,750 \\
\hline & $9,000,000$ & 12,750 & 12,750 & 12,750 & 12,750 & 12,750 & 12,000 \\
\hline & $1,0020,000$ & 12,750 & 12,750 & 12,000 & 12,000 & 12,000 & 12,000 \\
\hline & $1,0200,000$ & 12,000 & 12,000 & 12,000 & 12,000 & 12,000 & 12,000 \\
\hline & & \multicolumn{6}{|c|}{ TPS position (\%) } \\
\hline & & 56,250 & 62,250 & 68,250 & 74,250 & 80,250 & \\
\hline \multirow{16}{*}{$\begin{array}{l}\text { Engine speed } \\
(\mathrm{rpm})\end{array}$} & $1,200,000$ & 18,750 & 20,250 & 21,750 & 21,750 & 21,000 & \\
\hline & $1,680,000$ & 21,000 & 21,000 & 21,750 & 21,000 & 21,000 & \\
\hline & $1,980,000$ & 21,750 & 21,750 & 21,000 & 21,000 & 18,750 & \\
\hline & $2,460,000$ & 20,250 & 18,750 & 18,750 & 18,750 & 18,000 & \\
\hline & $3,000,000$ & 18,750 & 18,750 & 18,750 & 18,000 & 18,000 & \\
\hline & $3,540,000$ & 18,000 & 18,000 & 18,000 & 17,250 & 17,250 & \\
\hline & $4,020,000$ & 18,000 & 18,000 & 17,250 & 17,250 & 15,750 & \\
\hline & $4,500,000$ & 17,250 & 17,250 & 17,250 & 15,750 & 14,250 & \\
\hline & $4,980,000$ & 15,750 & 15,750 & 15,750 & 14,250 & 14,250 & \\
\hline & $5,520,000$ & 15,000 & 15,000 & 14,250 & 14,250 & 12,750 & \\
\hline & $6,000,000$ & 14,250 & 14,250 & 14,250 & 12,750 & 12,750 & \\
\hline & $7,020,000$ & 12,750 & 12,750 & 12,750 & 12,000 & 12,000 & \\
\hline & $7,980,000$ & 12,750 & 12,000 & 12,000 & 12,000 & 12,000 & \\
\hline & $9,000,000$ & 12,000 & 12,000 & 12,000 & 12,000 & 11,250 & \\
\hline & $1,0020,000$ & 12,000 & 12,000 & 11,250 & 11,250 & 9,750 & \\
\hline & $1,0200,000$ & 11,250 & 11,250 & 10,500 & 9,750 & 9,750 & \\
\hline
\end{tabular}

driving unit. The highest torque of the tested driving unit is recorded in the engine speed range from 6,500 to 7,500 rpm (Fig. 4). 
Table 4. Modified pre-ignition map.

\begin{tabular}{|c|c|c|c|c|c|c|c|}
\hline \multicolumn{8}{|c|}{ Modified ignition map } \\
\hline & & \multicolumn{6}{|c|}{ TPS position (\%) } \\
\hline & & 53,250 & 54,000 & 54,750 & 56,250 & 57,000 & 57,750 \\
\hline \multirow{16}{*}{$\begin{array}{l}\text { Engine speed } \\
\text { (rpm) }\end{array}$} & 780,000 & 9,000 & 9,000 & 9,000 & 9,000 & 9,000 & 9,000 \\
\hline & $1,200,000$ & 9,000 & 9,000 & 9,000 & 9,000 & 9,000 & 9,000 \\
\hline & $1,980,000$ & 9,000 & 9,000 & 9,000 & 9,000 & 9,000 & 9,000 \\
\hline & $2,460,000$ & 9,000 & 9,000 & 9,000 & 9,000 & 9,000 & 9,000 \\
\hline & $3,000,000$ & 15,000 & 15,000 & 15,000 & 15,000 & 15,000 & 15,000 \\
\hline & $3,540,000$ & 21,750 & 20,250 & 20,250 & 20,250 & 18,750 & 18,750 \\
\hline & $4,020,000$ & 20,250 & 20,250 & 18,750 & 18,750 & 18,750 & 18,000 \\
\hline & $4,500,000$ & 18,750 & 18,750 & 18,750 & 18,000 & 18,000 & 18,000 \\
\hline & $4,980,000$ & 18,750 & 18,750 & 18,000 & 15,000 & 15,750 & 15,750 \\
\hline & $5,520,000$ & 18,000 & 18,000 & 15,750 & 15,750 & 14,250 & 14,250 \\
\hline & $6,000,000$ & 14,250 & 14,250 & 14,250 & 12,750 & 12,750 & 12,750 \\
\hline & $7,020,000$ & 12,750 & 12,750 & 12,750 & 12,000 & 11,250 & 11,250 \\
\hline & $7,980,000$ & 12,000 & 11,250 & 11,250 & 9,750 & 9,750 & 9,750 \\
\hline & $9,000,000$ & 9,000 & 9,750 & 9,750 & 9,750 & 9,000 & 8,250 \\
\hline & $10,020,000$ & 8,250 & 8,250 & 8,250 & 8,250 & 8,250 & 8,250 \\
\hline & $10,200,000$ & 6,000 & 6,000 & 6,000 & 6,000 & 6,000 & 6,000 \\
\hline & & \multicolumn{6}{|c|}{ TPS position (\%) } \\
\hline & & 59,250 & 60,000 & 69,000 & 74,250 & 84,000 & \\
\hline \multirow{16}{*}{$\begin{array}{l}\text { Engine speed } \\
\quad(\mathrm{rpm})\end{array}$} & 780,000 & 9,000 & 9,000 & 9,000 & 9,000 & 9,000 & \\
\hline & $1,200,000$ & 9,000 & 9,000 & 9,000 & 9,000 & 9,000 & \\
\hline & $1,980,000$ & 9,000 & 9,000 & 9,000 & 9,000 & 9,000 & \\
\hline & $2,460,000$ & 9,000 & 9,000 & 9,000 & 9,000 & 9,000 & \\
\hline & $3,000,000$ & 15,000 & 15,000 & 15,000 & 15,000 & 15,000 & \\
\hline & $3,540,000$ & 18,000 & 18,000 & 18,000 & 17,250 & 17,250 & \\
\hline & $4,020,000$ & 18,000 & 18,000 & 17,250 & 17,250 & 15,750 & \\
\hline & $4,500,000$ & 17,250 & 17,250 & 17,250 & 15,750 & 14,250 & \\
\hline & $4,980,000$ & 15,750 & 15,000 & 15,000 & 12,750 & 12,750 & \\
\hline & $5,520,000$ & 14,250 & 12,750 & 12,750 & 11,250 & 11,250 & \\
\hline & $6,000,000$ & 12,750 & 11,250 & 11,250 & 9,750 & 9,750 & \\
\hline & $7,020,000$ & 11,250 & 9,750 & 9,750 & 9,000 & 9,000 & \\
\hline & $7,980,000$ & 9,750 & 9,000 & 8,250 & 8,250 & 8,250 & \\
\hline & $9,000,000$ & 8,250 & 6,750 & 6,750 & 6,000 & 6,000 & \\
\hline & $10,020,000$ & 8,250 & 8,250 & 6,750 & 6,000 & 6,000 & \\
\hline & $10,200,000$ & 6,000 & 5,250 & 5,250 & 3,750 & 3,750 & \\
\hline
\end{tabular}


Table 5. Fuel consumption values before and after modification.

\begin{tabular}{|c|c|c|c|c|c|c|c|}
\hline $\begin{array}{c}\text { Measurement } \\
\text { number }\end{array}$ & $\begin{array}{c}\text { Standard } \\
\text { engine }(\mathrm{km})\end{array}$ & $\begin{array}{c}\text { Optimised } \\
\text { engine }(\mathrm{km})\end{array}$ & Difference & $\begin{array}{c}\text { Standard max. } \\
\text { speed }(\mathrm{km} / \mathrm{h})\end{array}$ & $\begin{array}{c}\text { Optimised } \\
\text { max. speed } \\
(\mathrm{km} / \mathrm{h})\end{array}$ & $\begin{array}{c}\text { Standard } \\
\text { consumption } \\
(1 / 100 \mathrm{~km})\end{array}$ & $\begin{array}{c}\text { Optimised } \\
\text { consumption } \\
(1 / 100 \mathrm{~km})\end{array}$ \\
\hline 1. & 140 & 426 & 286 & 38 & 43 & 0.71 & 0.23 \\
\hline 2. & 131 & 415 & 284 & 35 & 41 & 0.76 & 0.24 \\
\hline 3. & 135 & 433 & 298 & 35 & 42 & 0.74 & 0.23 \\
\hline
\end{tabular}

\section{Results and Discussion}

Fuel consumption of the given piston combustion engine was determined according to the number of kilometres driven on one litre of fuel. The correct variant of the motor-management modification was verified during the testing process. The individual measurements were repeated three times - one after another and in the same weather conditions (temperature, pressure, and humidity of air) - in order to obtain reliable results. The engine was first tested with a standard (original) set-up, and subsequently after installation of the injection module and with the optimised data.

A large number of the fuel maps and pre-ignition maps that were applied during the whole test process served to determine their optimal combination with regard to minimal fuel consumption. Table 5 presents the measured fuel consumption values in the case of the standard engine and modified engine.

Installation of the injection module and optimising the data fields have a positive influence on reducing fuel consumption, and in this way the number of kilometres driven on one litre of fuel was increased significantly, namely by about $298 \mathrm{~km}$ in comparison with the standard engine application. Another relevant achievement, which represents a positive result of the described engine adjustments, is improving the engine's operational

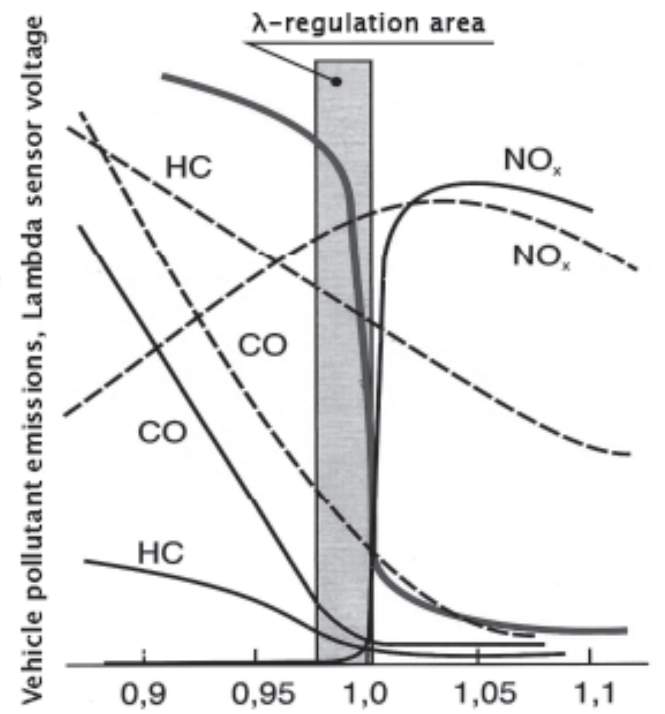

Fig. 5. Composition of emissions depending on the $\lambda$-value. flexibility and acceleration, which is a very important advantage in the starting phase of a competitive vehicle [10-11].

Determining the optimal combination of technical parameters during the test process has a decisive impact on various economic indicators: the number of kilometres travelled per litre of fuel, fuel consumption per 100 kilometers, engine efficiency, engine running costs, engine maintenance costs, engine wear, and so on.

Optimization has a positive impact on fuel consumption per 100 kilometers. Consumption decreased from 0.74 liters per 100 kilometers to 0.23 . Under experimental conditions, there are no economic benefits that are crucial, but in practice there have been significant savings in fuel costs.

In further research, it would be interesting to track the change in engine maintenance costs, wear at higher speeds, and a few more things. Also interesting is the impact of possible additional costs associated with engine operation, such as frequent oil changes.

The measuring equipment that recording of the $\lambda$-values during engine operation indicated the important fact that the engine is working with the lean fuel-air mixture $(\lambda>1)$ in the whole operational regime. This situation confirms the positive result that the performed engine modifications contributed to reducing exhaust gas emissions. Operating the engine in a rich working regime $(\lambda<1)$, i.e., with a redundancy of fuel, causes an increase of carbon monoxide (CO) and hydrocarbon (HC) emissions due to insufficient oxygen, because the rich fuel-air mixture is combusted incompletely.

The minimal values of the $\mathrm{HC}$ emissions are reached in the case that the $\lambda$-value is from the interval $1.1 \div 1.2$. Values of nitrogen oxide emissions $\left(\mathrm{NO}_{\mathrm{x}}\right)$ decrease in the lean mixture area because combustion temperature is reduced during engine operation in the lean working regime (Fig. 5) [12-15].

\section{Conclusions}

Research and development, which was performed in the area of the driving unit adjustment, resulted in a significant reduction of fuel consumption compared to the standard motor-management system. The engine speed level was increased thanks to a suitable modification of the engine control unit and in this way also heightened the maximal value of the experimental vehicle speed. 
Optimizing the driving unit improved the combustion process in order to reach higher levels of fuel consumption efficiency with a positive influence on the environment due to reduced carbon oxide emissions. The results of our research work also have been introduced internationally, namely at the international Shell Eco-Marathon competition in London. Our experimental vehicle, which was equipped with the innovated driving unit, presented itself with reliable operation and very favourable results.

\section{Acknowledgements}

This work was supported by the Slovak Research and Development Agency under the contract No. APVV-160259.

The article was written in the framework of Grant Projects: APVV-16-0259 "Research and development of combustion technology based on controlled homogenous charge compression ignition in order to reduce nitrogen oxide emissions of motor vehicles", VEGA 1/0473/17 "Research and development of technology for homogeneous charge self-ignition using compression in order to increase engine efficiency and to reduce vehicle emissions" and KEGA 041TUKE4/2017 "Implementation of new technologies specified for solution of questions concerning emissions of vehicles and transformation of them into the educational process in order to improve quality of education."

\section{References}

1. PUŠKKÁR M. Measuring method for feedback provision during development of fuel map in hexadecimal format for high-speed racing engines. Measurement 50 (1), 203, 2014.

2. HUNICZ J., KRZACZEK P. Detailed Speciation of Emissions from Low-Temperature Combustion in a Gasoline HCCI Engine. Pol. J. Environ. Stud. 25 (1), 137, 2016.

3. PUŠKKÁR M., BIGOŠ P. Method for accurate measurements of detonations in motorbike high speed racing engine. Measurement 45 (3), 529, 2012.

4. PUŠKÁR M., BIGOŠ P., PUŠKÁROVÁ P. Accurate measurements of output characteristics and detonations of motorbike high-speed racing engine and their optimization at actual atmospheric conditions and combusted mixture composition. Measurement 45 (5), 1067, 2012.

5. SROKA J. Z. Impact of Downsizing Technology on Operating Indicators for Combustion Engine Fed with Gaseous Fuel with Low Methane Content. Pol. J. Environ. Stud. 23 (4),1413, 2014.

6. PUŠKÁR M., BIGOŠ P. Measuring of acoustic wave influences generated at various configurations of racing engine inlet and exhaust system on brake mean effective pressure. Measurement 46 (9), 3389, 2013.

7. AMBROZIK A., AMBROZIK T., KURCZYŃSKI D., ŁAGOWSKI P. The Influence of Injection Advance Angle on Fuel Spray Parameters and Nitrogen Oxide Emissions for a Self-Ignition Engine Fed with Diesel Oil and FAME. Pol. J. Environ. Stud. 23 (6), 1917, 2014.

8. YASAR A., HAIDER R., TABINDA B.A., KAUSAR F., KHAN M.A. Comparison of Engine Emissions from Heavy, Medium, and Light Vehicles for CNG, Diesel, and Gasoline Fuels. Pol. J. Environ. Stud. 22 (4), 1277, 2013.

9. FITZGERALD R., STEEPER R., SNYDER J., HANSON R., HESSEL R. Determination of cycle temperatures and residual gas fraction for HCCI negative valve overlap operation. SAE Int. J. Engines 3 (1), 124, 2010.

10. SZEWCZYŃSKA M., POŚNIAK M., DOBRZYŃSKA E., PYRZYNSKA K., BARANIECKA J. Polycyclic aromatic hydrocarbons distribution in fine and ultrafine particles emitted from diesel engine to the air. Pol. J. Environ. Stud. $22(2), 553,2013$

11. FITZGERALD R., STEEPER R. Thermal and chemical effects of NVO fuel injection on HCCI combustion, SAE Int. J. Engines 3 (1), 46, 2010.

12. HUNICZ J. An experimental study of negative valve overlap injection effects and their impact on combustion in a gasoline HCCI engine. Fuel 117, 236, 2014.

13. SZEWCZYŃSKA M., DĄBROWSKA J., PYRZYŃSKA K. Polycyclic Aromatic Hydrocarbons in the Particles Emitted from the Diesel and Gasoline Engines. Pol. J. Environ. Stud. 26 (2), 801, 2017.

14. ZAJĄC G., SZYSZLAK-BARGŁOWICZ J., SŁOWIK T., KURANC A., KAMIŃSKA A. Designation of Chosen Heavy Metals in Used Engine Oils Using the XRF Method. Pol. J. Environ. Stud. 24 (5), 2277, 2015.

15. BALTRENAS P., PALIULIS D., VAIŠKUNAITE R. Experimental Investigations and Evaluation of Pollutant Emissions into Ambient Air by Rolling Stock Engines. Pol. J. Environ. Stud. 23 (3), 673, 2014. 